\title{
Isolation of Yersinia spp. from cases of diarrhoea in Iraqi infants and children
}

T.A. Kanan ${ }^{1}$ and Z.A. Abdulla ${ }^{1}$

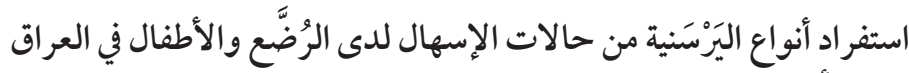

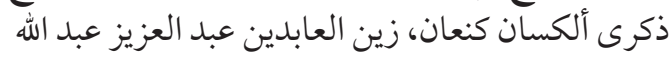

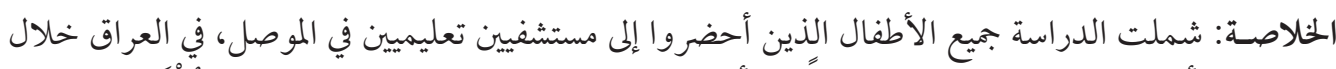

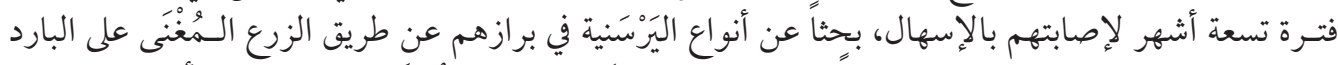

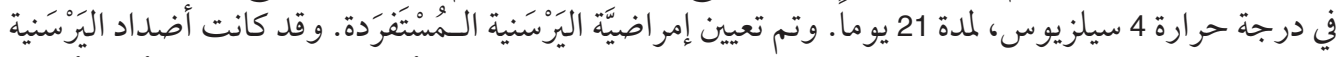

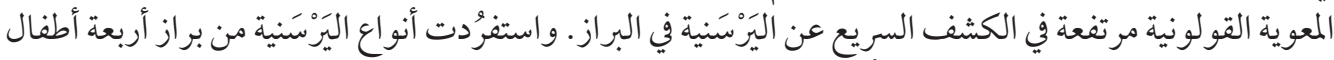

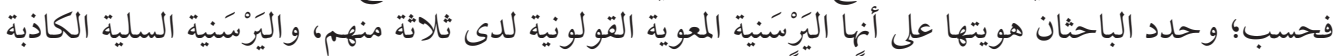

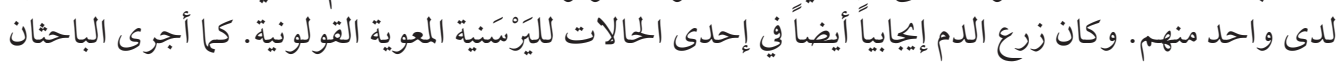

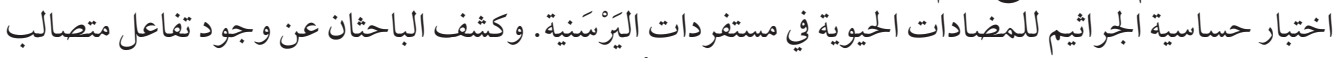

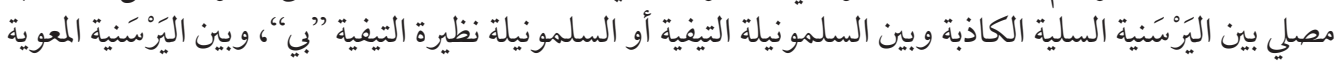
القولونية والبروسيلة.

ABSTRACT All 250 children presenting with diarrhoea at 2 teaching hospitals in Mosul, Iraq over a 9-month period were studied for the presence of Yersinia spp. in stools by cold-enrichment culture at $4{ }^{\circ} \mathrm{C}$ for 21 days. Pathogenicity of the isolated Yersinia was determined. Antibodies to $Y$. enterocolitica were raised for rapid Yersinia detection in the stool. Yersinia spp. were isolated from the stools of only 4 patients; 3 isolates were identified as $Y$. enterocolitica and 1 was $Y$. pseudotuberculosis. The blood culture was also positive for $Y$. enterocolitica in 1 case. The antibiogram test for the isolated Yersinia was determined. Cross-reaction between Y. pseudotuberculosis and Salmonella typhi or S. paratyphi $\mathrm{B}$, and between $\mathrm{Y}$. enterocolitica and Brucella was detected serologically.

Isolement de Yersinia spp. à partir de cas de diarrhée chez des nourrissons et des enfants iraquiens

RÉSUMÉ Tous les 250 enfants qui ont présenté une diarrhée dans deux hôpitaux universitaires de Mosul (Iraq) pendant une période de 9 mois ont fait l'objet d'une recherche de Yersinia spp. dans les selles par le placement des cultures à une température de $4{ }^{\circ} \mathrm{C}$ (technique d'enrichissement par le froid) pendant 21 jours. La pathogénicité de la bactérie Yersinia isolée a été établie. Des anticorps anti-Y enterocolitica ont été cultivés afin de permettre la détection rapide de Yersinia dans les selles. Des Yersinia spp. ont été isolées à partir des selles de 4 sujets seulement ; Y. enterocolitica a été identifiée dans 3 cas et $Y$. pseudotuberculosis dans 1. L'hémoculture était également positive à $Y$. enterocolitica dans 1 cas. On a déterminé l'antibiogramme pour la bactérie Yersinia isolée. La réaction croisée entre Y. pseudotuberculosis et Salmonella typhi ou S. paratyphi B, et entre Y. enterocolitica et Brucella a été détectée sérologiquement.

\footnotetext{
${ }^{1}$ Department of Microbiology, College of Medicine, Mosul, Iraq (Correspondence to Z.A. Abdulla: pdrzainabdn@yahoo.com).

Received: 11/05/06; accepted: 27/09/06
}

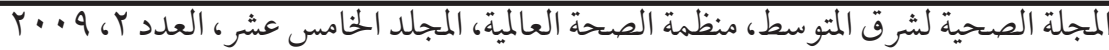




\section{Introduction}

Yersinia spp. are gram-negative rods or coccobacilli with bipolar staining that belong to the Enterobacteriaceae family [1]. Eleven species are known, but only 3 are important human pathogens; $Y$. enterocolitica is the most common of these, while $Y$. pseudotuberculosis is less frequent, and $Y$. pestis is rare [2].

Yersiniosis is a clinical condition caused by infection with low- and high-pathogenic species of Yersinia: Y. enterocolitica and Y. pseudotuberculosis [3,4]. The disease is characterized by symptoms of gastroenteritis and/or vomiting with abdominal pain. Yersinia infection ranges from asymptomatic hosts to patients with life-threatening sepsis, especially in children [1]. Several syndromes are associated with $Y$. enterocolitica infection in children, including enterocolitis, pseudoappendicitis syndrome, extraintestinal infections, bacteraemia and Izumi fever.

Transmission is primarily via ingestion of contaminated foods, water and milk or ingestion of uncooked meat products, especially pork [5]. The majority of cases of enterocolitis are seen in children aged $1-4$ years $[6,7]$. Moreover, these infections show a modest predilection for males, with male to female ratio of 1.7:1.

Yersiniosis is a rare disease in Muslim countries due to the scarcity of pork consumption. The incidence of yersiniosis is reported to be $10 \%-30 \%$ in European countries and $0.06 \%-2 \%$ in Muslim ones [8,9]. The weather is another factor affecting the growth and transmission of Yersinia. A cold climate facilitates pathogenesis; this is encountered most of the year in European countries, whereas in temperate countries such as Iraq it is mainly in the winter months.

The aim of the present study was to investigate the role of Yersinia as a cause of diarrhoea among infants and children in the Iraqi community since no local data about the subject are available.

\section{Methods}

\section{Patients}

The study sample was all 250 infants and children suffering from diarrhoea who were admitted to the Department of Paediatrics in Ibn Alatheer and Ibn Seena teaching hospitals, Mosul, Iraq from October 2003 to June 2004. The duration of diarrhoea ranged from 1 day to 1 month, but 188 cases $(75 \%)$ had duration of $<5$ days. Besides diarrhoea, the patients presented with fever in 195 cases $(78 \%)$ and vomiting in 188 cases $(75 \%)$. The patients were 139 males $(55.6 \%)$ and 111 females (44.4\%), with mean age 13.9 [standard deviation (SD) 15.2] months, range 12 days to 12 years.

The cases were subdivided into 2 groups according to the method used for identification. A subsample of 100 patients underwent full bacteriological identification from the stool and blood samples to identify the concomitant bacteria encountered in Yersinia positive or negative cases and to study the survival of Yersinia and other bacteria in cold enrichment. The whole group of 250 patients underwent rapid identification of Yersinia from the stool samples only to determine the highest possible number of cases of yersiniosis.

\section{Stool culture}

Ordinary culture was done for the subsample of 100 patients. Stool samples were cultured directly on MacConkey agar (Oxoid, UK) and Salmonella-Shigella agar (Himedia, India) and incubated for 24 hours at $25^{\circ} \mathrm{C}$.

Cold enrichment was done for all cases. Faecal samples were cultured in phosphate

المجلة الصحية لشرق المتوسط، منظمة الصحة العالمية، المجلد الخامس عشر، العدد ب، 9 ·. 
buffered saline, incubated for 3 weeks at $4{ }^{\circ} \mathrm{C}$ and subcultured on MacConkey and Salmonella-Shigella agar every 7 days. The plates were incubated at $25^{\circ} \mathrm{C}$ for $24-48$ hours according to Sonnenwirth and Jarett [8].

\section{Blood culture}

The blood for culture was taken before the administration of antibiotics. The skin at the vein puncture was prepared using bactericidal disinfectant ( $2 \%$ solution of iodine and $70 \%$ alcohol). The blood was mixed with 10 times its volume of brain-heart infusion (BHI) broth in bottles. The cultures were incubated at $25^{\circ} \mathrm{C}$ for 15 days. Each sample was subcultured on blood and MacConkey agars after 7 and 15 days of incubation. Positive cultures showed turbidity; negative ones showed a layer of sediment of red blood cells covered by pale yellow transparent broth.

\section{Pathogenicity tests}

The isolated Yersinia spp. were subjected to 3 different pathogenicity tests to differentiate between the pathogenic and the non-pathogenic strains: the autoagglutination test, the crystal violet binding test and animal inoculation.

\section{Auto-agglutination test}

Two tubes of glucose-phosphate-peptone water were inoculated with a colony of Yersinia; 1 tube was incubated at $25^{\circ} \mathrm{C}$ and 1 tube at $35-37^{\circ} \mathrm{C}[2]$.

\section{Crystal violet binding test}

Colonies of Yersinia were cultured in BHI broth (Biokit, Spain) for 18 hours at $22-26^{\circ} \mathrm{C}$. Subculture was done on $2 \mathrm{BHI}$ agar plates (Oxoid, UK); 1 plate was incubated at $25^{\circ} \mathrm{C}$ and 1 plate at $37^{\circ} \mathrm{C}$ for 30 hours [2].

\section{Animal inoculation}

Three animal pathogenicity tests were done to determine the pathogenicity of Yersinia and their systemic and histopathological effects.

Intraperitoneal infection of rabbits was done by culturing $Y$. enterocolitica and $Y$. pseudotuberculosis in nutrient broth for 24 hours, serial dilution was done in normal saline and 3 rabbits were injected intraperitoneally with $3 \times 10^{7}$ cells $/ \mathrm{mL}$. One rabbit was injected with $Y$. pseudotuberculosis and 2 with $Y$. enterocolitica.

Mouse infection was done by culturing the bacteria in BHI broth for 24 hours at $25^{\circ} \mathrm{C}$, and serial dilutions were done in physiological saline. A group of 6-8-weekold white mice was injected intraperitoneally with $0.1 \mathrm{~mL}$ and $0.2 \mathrm{~mL}$ in dilutions of $3 \times 10^{6}$ cells $/ \mathrm{mL}$ and $3 \times 10^{7}$ cells $/ \mathrm{mL}$. On the 5 th post-infection day, the mice were killed and the liver, spleen, intestine and mesenteric lymph nodes were extracted and sent for the histopathological study at the Department of Histopathology, College of Medicine, Mosul, Iraq.

Detection of enterotoxins of the isolated Yersinia was assessed in infant mice. The bacteria were cultured by shaking in trypticase-soy broth (Oxoid, UK) containing $0.6 \%$ (wt./vol.) yeast extract at $28{ }^{\circ} \mathrm{C}$ for 48 hours. Bacterial cells were removed by cold centrifugation, and $0.1 \mathrm{~mL}$ of the supernatant was administered orally to 2-3day-old mice in a dilution of $3 \times 10^{6}$ cells/ $\mathrm{mL}$. After 2 hours, the mice were killed and through abdominal exploration, swelling of the intestines of the infected mice was noted. The mean ratio of intestinal weight to the remaining body weight was calculated. Ratios greater than 0.08 were considered indicative of enterotoxin production according to Grant et al. [9].

\section{Anti-Yersinia antibody production}

The specificity of the raised anti-Yersinia antibodies was tested using Yersinia and other microorganisms that possibly cross-react. 
Antibody was raised in 6-8-week-old mice. Three mice were given repeated injections of $Y$. enterocolitica, the doses varied from $0.1-0.2 \mathrm{~mL}$ in a dilution of $3 \times 10^{6}$ bacterial cells $/ \mathrm{mL}$. These injections were given in 5 doses, 4 intraperitoneally and 1 intravenously with 6 days interval between the doses. The animals were bled and the serum was separated and frozen at $-20{ }^{\circ} \mathrm{C}$ until use. Detection of anti-Yersinia antibodies in serum was done by mixing a drop of serum taken from infected adult mice with a colony taken from a pure culture of $Y$. enterocolitica, and obvious agglutination was seen in less than 1 minute.

Bacterial suspensions of 4 common genera of microorganisms that have possible cross-reaction with Yersinia were used to test the raised anti-Yersinia antibodies. These were E. coli, Salmonella, Klebsiella and Proteus spp.

\section{Serological tests}

The following serological tests were done for the subsample of 100 patients, according to the methods of Osman et al. [10].

- Rapid slide agglutination test (Widal test)

- Brucella agglutination test (rose-Bengal test)

- 2-mercaptoethanol (2ME) test for both Widal and Brucella agglutination tests.

\section{Antimicrobial sensitivity test}

Selected colonies were suspended in $0.85 \%$ saline solution to achieve a turbid suspension and spread on Muller-Hinton agar plates (Oxoid, UK) using cotton swabs. The antibiogram was done for both Yersinia and non-Yersinia isolates.

\section{Results}

\section{Stool culture}

The cold enrichment culture was done for all 250 patients studied. The total number of Yersinia isolates from the stool culture of all patients studied was $4(1.6 \%) ; 3$ of these isolates were $Y$. enterocolitica and 1 was $Y$. pseudotuberculosis (Table 1). The 3 isolates of $Y$. enterocolitica were recovered from children aged 1-11 months, while the 1 strain of $Y$. pseudotuberculosis was isolated from a 5-year-old child.

Yersinia was not isolated by the 7 days of cold enrichment, but 3 isolates appeared by 14 days and 1 isolate by 21 days (Table 2).

\section{Blood culture}

Blood culture for the subsample of 100 cases was positive for $Y$. enterocolitica in 1 case $(1 \%)$ only, an infant aged 1 month. This patient also had positive stool culture for the same microorganism. The stool and the blood isolates showed similar morphological and biochemical characteristics of $Y$. enterocolitica (Table 3 ).

\section{Pathogenicity tests}

Auto-agglutination tests

In auto-agglutination tests, after 24 hours the tube incubated at $25^{\circ} \mathrm{C}$ showed some turbidity of bacterial growth, while the tube incubated at $37^{\circ} \mathrm{C}$ showed agglutination of

\begin{tabular}{lcccc}
\hline \multicolumn{6}{l}{ Table 1 Incidence of Yersinia spp. isolated from the stool culture of 250 patients } \\
\hline Species & No. of isolates & $\begin{array}{c}\% \text { of patients } \\
(\boldsymbol{n}=\mathbf{2 5 0})\end{array}$ & $\begin{array}{c}\% \text { of isolates } \\
(\boldsymbol{n}=\mathbf{4})\end{array}$ & $\begin{array}{c}\text { Incidence } \\
\text { (per 1000 patients) }\end{array}$ \\
\hline Y. enterocolitica & 3 & 1.2 & 75 & 12 \\
Y. pseudotuberculosis & 1 & 0.4 & 25 & 4 \\
Total & 4 & 1.6 & 100 & 16 \\
\hline
\end{tabular}

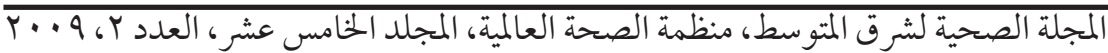




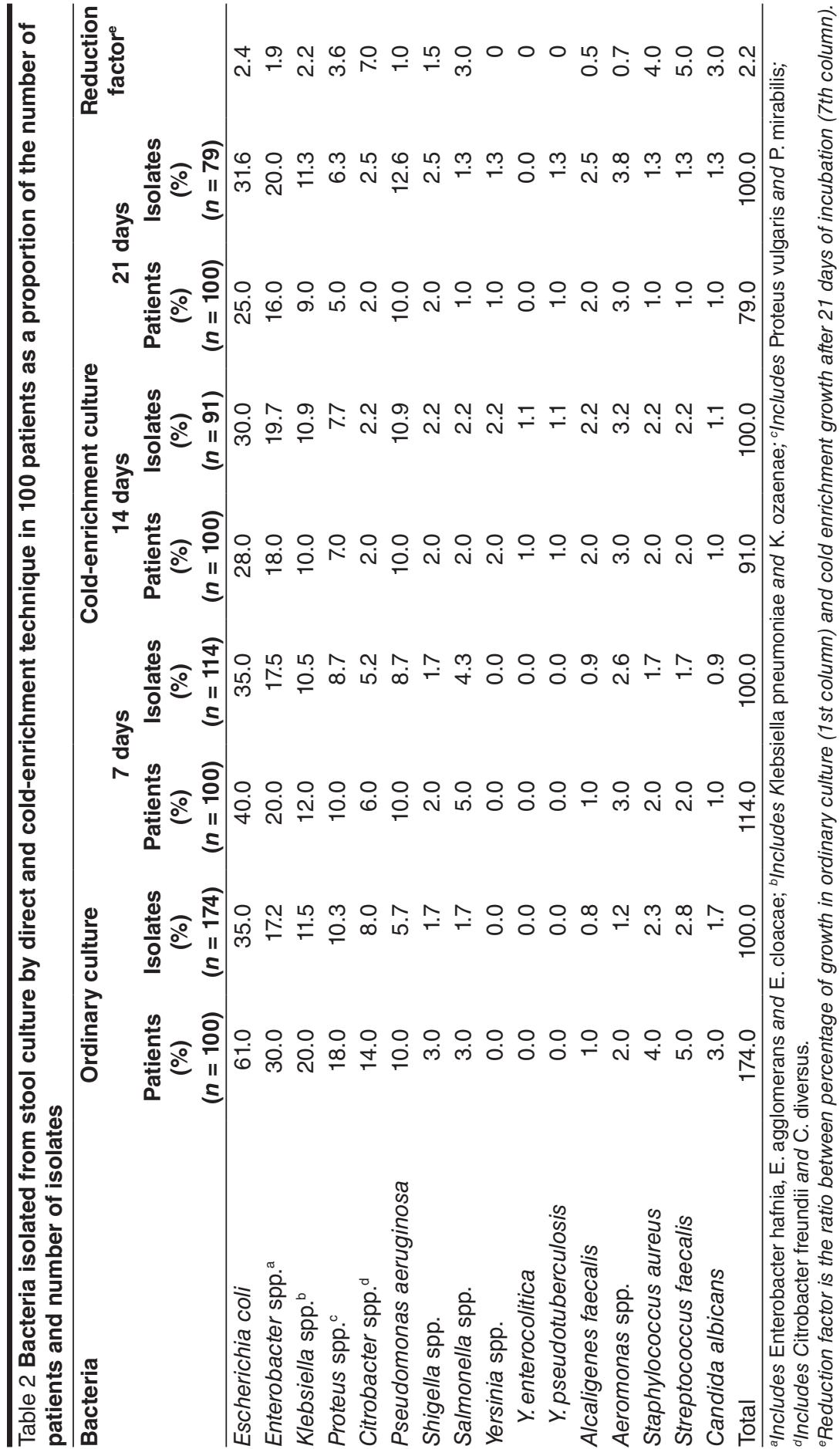

المجلة الصحية لشرق المتوسط، منظمة الصحة العالمية، المجلد الخامس عشر، العدد ب، 9 ·. 
bacteria along the walls and the bottom of the tube with clear supernatant fluid.

\section{Crystal violet binding test}

The crystal violet binding test showed that colonies grown at $37^{\circ} \mathrm{C}$ bound to the stain, while colonies grown at $25^{\circ} \mathrm{C}$ did not.

\section{Animal pathogenicity tests}

In the animal pathogenicity tests the rabbit that was given $Y$. pseudotuberculosis died after the 3rd injection (12 days), the remaining 2 rabbits that were given $Y$. enterocolitica died after the 4th injection (18 days).

The hematoxylin-eosin-stained sections of all the tissues taken from the group of animals injected with $0.1 \mathrm{~mL}$ and 0.2 $\mathrm{mL}$ of $3 \times 10^{6}$ bacterial cells $/ \mathrm{mL}$ showed no histopathological changes. However, in the group of animals injected with 0.2 $\mathrm{mL}$ of $3 \times 10^{7}$ bacterial cells $/ \mathrm{mL}$, their tissues showed chronic inflammatory cell infiltrate, mainly lymphocytes. These changes were seen in the intestine and the mesenteric lymph nodes. Granulomatous changes were seen in the lungs. No inflammatory changes were noted either in the liver or the spleen.

Enterotoxin production was positive in infant mice with ratios of intestine:total body weight of 0.08 and 0.083 .

Table 3 Bacteria isolated from blood culture of 100 patients

\begin{tabular}{lcrc}
\hline Bacteria & \multicolumn{2}{c}{$\begin{array}{c}\text { Patients } \\
(\boldsymbol{n}=\mathbf{1 0 0})\end{array}$} & $\begin{array}{c}\text { Isolates } \\
(\boldsymbol{n}=\mathbf{1 2})\end{array}$ \\
& No. & \multicolumn{1}{c}{$\%$} & \multicolumn{1}{c}{$\%$} \\
\hline Staphylococcus aureus & 5 & 5.0 & 41.7 \\
Escherichia coli & 4 & 4.0 & 33.3 \\
Enterobacter hafnia & 1 & 1.0 & 8.3 \\
Yersinia enterocolitica & 1 & 1.0 & 8.3 \\
Listeria monocytogenes & 1 & 1.0 & 8.3 \\
Total & 12 & 12.0 & 100.0 \\
\hline
\end{tabular}

\section{Anti-Yersinia antibody production}

None of the bacterial suspensions tested (E. coli, Salmonella, Klebsiella or Proteus spp.) showed macroscopical agglutination. The antibody reacted only with $Y$. enterocolitica, as a positive result was noted when the stool of a yersiniosis patient was mixed with the antiserum.

\section{Serological tests}

The Widal agglutination test was positive in 6 out of 100 patients tested. Among these positive cases, only 1 had Y. pseudotuberculosis infection. This microorganism was only identified from the stool and not from the blood. This patient had anti-O antibodies against Salmonella typhi $(1 / 160)$ and Salmonella paratyphi B (1/320) without anti-H antibodies. The $2 \mathrm{ME}$ Widal test of this patient revealed negative agglutination for anti-O antibodies of both $S$. typhi and $S$. paratyphi B.

The Brucella agglutination test was positive in 1 patient only (1\%) with a titre of $1 / 160$. This patient had positive stool and blood cultures for $Y$. enterocolitica and negative 2ME Brucella agglutination test (which detects active recent infection).

\section{Antimicrobial sensitivity tests}

In the antibiogram tests, 4 isolates of $Y$. enterocolitica and 1 of $Y$. pseudotuberculosis showed full sensitivity to gentamicin, cefotaxime, chloramphenicol, amikacin, ciprofloxacin and norfloxacin. Two of the $3 Y$. enterocolitica strains were sensitive to nalidixic acid and tetracycline, while $Y$. pseudotuberculosis was also sensitive to these 2 drugs (Table 4).

All Yersinia spp. isolated from the stool were resistant to rifampin, imipenem and ceftazidime. Y. pseudotuberculosis showed an intermediate sensitivity to amoxycillin and cephalexin, while $Y$. enterocolitica isolates were resistant to these 2 drugs. 


\section{Discussion}

In this study $Y$. enterocolitica was isolated from 3 children aged 1-11 months, while $Y$. pseudotuberculosis was isolated from a 5-year-old child. These results are in agreement with previous studies in which $Y$. enterocolitica infection was found in infants and young children whereas $Y$. pseudotuberculosis infected older children aged 5-15 years $[2,11]$.

$Y$. enterocolitica was isolated from the blood of an infant aged 1 month, who also had a positive stool culture for the same microorganism. This result is supported by previous studies which reported that concomitant bacteraemia was seen in $20 \%-30 \%$ of infants younger than 3 months infected with this microorganism [12]. However, we could not isolate $Y$. pseudotuberculosis from the blood of any cases although it was found in the stool of an older child (aged 5 years).
The pathogenicity tests, the auto-agglutination test, crystal violet binding test and Yersinia inoculation in animals indicated that all Yersinia isolates were pathogenic and the pathogenicity of $Y$. pseudotuberculosis was greater than that of $Y$. enterocolitica as determined by animal inoculation. This finding is in accordance with many previous studies $[1,4]$. Also Delor and Cornelis considered that the Yersinia enterotoxin was the cause of diarrhoea in young rabbits and consequently was the major factor involved in the $Y$. enterocolitica-associated diarrhoea in young children. [13].

The effect of $Y$. enterocolitica isolates injected into adult mice on the lymph nodes, intestine and lungs indicated that the primary site of Yersinia infection and multiplication was the lymphatic tissue. This result is in keeping with Grant et al. [9] and Iwobi et al. [4] who found that the Peyer's patches

\begin{tabular}{|c|c|c|c|c|}
\hline \multirow[t]{3}{*}{ Antibiotic } & \multicolumn{4}{|c|}{ No. of sensitive strains } \\
\hline & \multicolumn{3}{|c|}{ Y. enterocolitica } & \multirow{2}{*}{$\begin{array}{c}\text { Y. pseudotuberculosis } \\
\text { Stool } \\
(n=1)\end{array}$} \\
\hline & $\begin{array}{c}\text { All isolates } \\
(n=4)\end{array}$ & $\begin{array}{c}\text { Stool } \\
(n=3)\end{array}$ & $\begin{array}{l}\text { Blood } \\
(n=1)\end{array}$ & \\
\hline Amoxicillin & 0 & 0 & 0 & 1 \\
\hline Cefotaxime & 4 & 3 & 1 & 1 \\
\hline Cephalexin & 0 & 0 & 0 & 1 \\
\hline Ceftazidime & 0 & 0 & 0 & 0 \\
\hline Imipenem & 0 & 0 & 0 & 0 \\
\hline Gentamicin & 4 & 3 & 1 & 1 \\
\hline Chloramphenicol & 4 & 3 & 1 & 1 \\
\hline Tetracycline $^{a}$ & 3 & 2 & 1 & 1 \\
\hline Nalidixic acid & 3 & 2 & 1 & 1 \\
\hline Trimethoprim & 1 & 1 & 0 & 1 \\
\hline Rifampin & 0 & 0 & 0 & 0 \\
\hline Amikacin & 4 & 3 & 1 & 1 \\
\hline Netilimicin & 1 & 1 & 0 & 0 \\
\hline Piperacillin & 1 & 1 & 0 & 0 \\
\hline Ciprofloxacin $^{a}$ & 4 & 3 & 1 & 1 \\
\hline Norfloxacin ${ }^{a}$ & 4 & 3 & 1 & 1 \\
\hline
\end{tabular}

These antibiotics are not suitable for use in children. 
of the intestine were the primary sites for infection with Yersinia. Moreover, enterotoxin production was positive in infant mice with ratios of intestine:total body weight of 0.08 and 0.083 . This result is in accordance with Nunes and Ricciardi [14] and Grant et al. [9] who considered intestinal swelling and ratios of 0.08 and above as indicators of enterotoxin production.

The isolation of Yersinia from the stool requires at least 2-3 weeks of cold enrichment culturing which renders this method laborious for routine work. Therefore, it is recommended that culturing is done by more practical methods such as serological tests using the specific antibody agglutination test.

The specificity of the raised anti-Yersinia antibody was tested using Yersinia and other microorganisms that possibly crossreact with it: the antibody reacted only with $Y$. enterocolitica. Consequently, this serological method was used as a possible alternative test for the diagnosis of yersiniosis. We showed that $Y$. enterocolitica could cross-react with Brucella and yield a false-positive rose-Bengal test in Brucella non-infected patients. Many researchers have demonstrated the cross-reaction between $Y$. enterocolitica serotype 0:9, and
Brucella abortus and B. melitensis [15,16]. It is possible that $Y$. enterocolitica isolated in the present study may belong to serotype $0: 9$ as it is the main serotype that can crossreact with Brucella. Cross-reaction was also found between $Y$. pseudotuberculosis and group B and D Salmonella spp. This is in keeping with other studies $[12,17]$.

The most effective drugs (full sensitivity) in treating yersiniosis were gentamicin, cefotaxime, chloramphenicol and tetracycline. This result is in agreement with that of Tzelepi et al. [18]. These antibiotics were effective against Yersinia isolated from both the stool and the blood. Also, the full resistance of $Y$. enterocolitica to both amoxicillin and cephalexin agrees with Tzelepi et al., who mentioned that $Y$. enterocolitica produces chromosomally determined $\beta$-lactamases that cause resistance to these 2 antibiotics [18]. The sensitivity of the single isolate of $Y$. pseudotuberculosis to amoxycillin and cephalexin contradicts Morris's opinion that this microorganism was resistant to these antibiotics [14]. However, these results are in accordance with reports by Campbell and Dennis [11]. Such discrepancies might be attributed to strain or biotype variations.

\section{References}

1. Rakin A et al. Common and specific characteristics of high pathogenicity islands of Yersinia enterocolitica. Infection and immunity, 1999, 67(10):5265-74.

2. Yersisia enterocolitica and Yersisia pseudotuberculosis. Ch. 8. In: Bacteriological analytical manual online. Rockville, Maryland, US Food and Drug Administration, Center of Food Safety and Applied Nutrition, 2001 (http://www.cfsan.fda.gov/ ebam/bam-8. html, accessed 5 July 2008).

3. Carniel E, Guilvout I, Prentice M. Characterization of a large chromosomal high pathogenicity islands in biotype 1B Yersinia enterocolitica. Journal of bacteriology, 1996, 178(23):6743-51.

4. Iwobi $A$ et al. Novel virulence-associated type II secretion system unique to high-pathogenicity Yersinia enterocolitica. Infection and immunity, 2003, 71(4):1872-9.

5. Fukushima $\mathrm{H}$ et al. Geographical heterogeneity between Far Eastern and Western countries in prevalence of the virulence plasmid, the superantigen Yersinia pseudotuberculosis-derived mitogen,

المجلة الصحية لشرق المتوسط، منظمة الصحة العالمية، المجلد الخامس عشر، العدد Y، 9.?Y 
and the high-pathogenicity island among Yersinia pseudotuberculosis strains. Journal of clinical microbiology, 2001, 39(10):3541-7.

6. Cleary TG. Yersinia. In: Behrman RE, Kliegman RM, Jenson HB, eds. Nelson textbook of paediatrics, 16th ed. Philadelphia, WB Saunders, 2000:857-60.

7. Logsdon L, Mecsas J. Requirement of the Yersinia pseudotuberculosis effectors $\mathrm{YopH}$ and YopE in colonization and persistence in intestinal and lymph tissues. Infection and immunity, 2003, 71(8):4595-607.

8. Sonnenwirth AC, Jarett L, eds. Gradwohl's clinical laboratory methods and diagnosis, 7th ed. Saint Louis, Missouri, Mosby, 1990.

9. Grant T, Bennett-Wood V, Robins-Browne RM. Identification of virulence-associated characteristics in clinical isolates of Yersinia enterocolitica lacking classical virulence markers. Infection and immunity, 1998, 66(3):1113-20.

10. Osman OA et al. Evaluation of variable diagnostic modalities of typhoid fever. Associated medical journal, 2000, 24(3):1-8.

11. Campbell GL, Dennis DT. Plague and other Yersinia infections. In: Fauci AS et al. eds. Harrison's principles of internal medicine, 14th ed. Columbus, Ohio, McGraw-Hill, 1998:975-83.
12. Morris JG. Yersinia infections. In: Bennett L, Plum F, eds. Cecil textbook of medicine, 20th ed, volume 2. Philadelphia, WB Saunders, 1996:1661-2.

13. Delor I, Cornelis GR. Role of Yersinia enterocolitica Yst toxin in experimental infection of young rabbits. Infection and immunity, 1992, 60(10):4269-77.

14. Nunes MP, Ricciardi ID. Detection of Yersinia enterocolitica heat-stable enterotoxin by suckling mouse bioassay. Journal of clinical microbiology, 1981, 13(4):783-6.

15. Al-Mariri A et al. Yersinia enterocolitica as a vehicle for a naked DNA vaccine encoding Brucella abortus bacterioferritin or p39 antigen. Infection and immunity, 2002, 70(4):1915-23.

16. Díaz-Aparicio $E$ et al. Comparative analysis of Brucella serotype $A$ and $M$ and Yersinia enterocolitica 0:9 polysaccharides for serological diagnosis of brucellosis in cattle, sheep, and goats. Journal of clinical microbiology, 1993, 31(12):3136-41.

17. Collee JG et al., eds. Mackie and McCartney practical medical microbiology. New York, Churchill Livingstone, 1996:1661-2.

18. Tzelepi E et al. Antibiotic susceptibilities of Yersinia enterocolitica and $Y$. intermedia isolates from aquatic environments. Journal of medical microbiology, 1999, 48:157-60. 